Article

\title{
Combination of Ascophyllum nodosum Extract and Humic Acid Improve Early Growth and Reduces Post-Harvest Loss of Lettuce and Spinach
}

\author{
Monica Sandepogu ${ }^{1}$, Pushp Sheel Shukla ${ }^{1}$, Samuel Asiedu ${ }^{2}$, Svetlana Yurgel ${ }^{2}$ and \\ Balakrishnan Prithiviraj ${ }^{1, *}$ \\ 1 Marine Bio-products Research Laboratory, Department of Plant, Food and Environmental Sciences, \\ Dalhousie University, Truro, NS B2N 5E3, Canada; s.monica@dal.ca (M.S.); pushpsheel.shukla@dal.ca (P.S.S.) \\ 2 Department of Plant, Food and Environmental Sciences, Dalhousie University, Truro, NS B2N 5E3, Canada; \\ sasiedu@dal.ca (S.A.); syurgel@dal.ca (S.Y.) \\ * Correspondence: bprithiviraj@dal.ca
}

Received: 21 October 2019; Accepted: 7 November 2019; Published: 11 November 2019

\begin{abstract}
Leafy vegetables like lettuce and spinach are prone to significant post-harvest losses during handling and storage. The pre-harvest treatment of crops with biostimulants offers a sustainable strategy for reducing post-harvest losses. Earlier studies focused on the effect of plant biostimulants applied individually. In this study, we studied the efficacy of a combined application of two commonly used plant biostimulants: Ascophyllum nodosum extract (ANE) and humic acid (HA). Interestingly, the combination of both biostimulants improved early growth of lettuce and spinach compared to ANE and HA alone. Among the combinations used in this study, $0.25 \%$ ANE $+0.2 \%$ HA produced significantly higher fresh and dry biomass in lettuce and spinach compared to the other treatments and the control. Pre-harvest treatment of combination of $0.25 \%$ ANE and $0.2 \%$ HA significantly reduced the loss of fresh biomass during post-harvest storage. The combination of $0.25 \%$ ANE and $0.2 \%$ HA reduced lipid peroxidation during storage with an increase in total ascorbate, phenolic, and antioxidant capacity of spinach and lettuce. These results suggest that a combination of ANE and HA reduces post-harvest losses of spinach and lettuce more effectively than when applied individually.
\end{abstract}

Keywords: biostimulants; seaweed extract; plant growth; spinach; lettuce; post-harvest loss

\section{Introduction}

Plant biostimulants are defined as substances that, when applied to plants, have positive effects on growth and productivity [1]. Biostimulants regulate different physiological processes and improve plant's tolerance to abiotic stresses [2]. Currently accepted plant biostimulants include seaweed extracts, humic substances, chitin and chitosan derivatives, amino acids, protein hydrolysates, and microbes. Seaweed extracts and humic acids are widely used in agriculture and the horticulture industry for improving plant growth and stress tolerance [1,3-5].

Seaweeds have been used as fertilizers and soil conditioning agents since ancient times [1,6,7]. The most widely researched seaweed as a plant biostimulant is Ascophyllum nodosum, a marine brown alga, found along the Atlantic coast of North America and Northern Europe [6,8,9]. Ascophyllum nodosum extract (ANE) contains bioactive compounds such as polysaccharides, alginates, vitamins, organic osmolytes, and hormone-stimulating substances that aid in plant growth and establishment [9-11]. ANE application enhances plant growth and development by increasing seed germination, root and shoot growth, and nutrient uptake [6]. ANE also improves plant growth by regulating phytohormone biosynthesis [12]. 
Humic acids (HAs) are naturally occurring complex macromolecules of decomposed organic matter that improves plant growth by chelating nutrients and buffering $\mathrm{pH}$ [13]. HAs are rich in mineral nutrients like sodium $(\mathrm{Na})$, potassium $(\mathrm{K})$, magnesium $(\mathrm{Mg})$, zinc $(\mathrm{Zn})$, calcium $(\mathrm{Ca})$, iron $(\mathrm{Fe})$, and copper $(\mathrm{Cu})$ and organic acid [13,14]. Humic acids improve plant growth and development [14]. Humic acids promote seed germination, root growth, enhanced nutrient uptake, improved stress tolerance, soil aggregation, water-holding capacity, and soil aeriation [15]. They also stimulate biosynthesis of growth-promoting hormones like auxins, gibberellins, and cytokinins during plant growth [16].

Few studies have reported synergistic effects of the combination of biostimulants on the growth and physiology of plants. In previous reports, the application of ANE, HA, and propiconazole on Festuca arundinacea have shown to reduce heat injury and enhance post-transplant rooting and quality of sod [17]. Humic acid and plant growth-promoting rhizobacteria (PGPR) Bacillus subtilis, when applied in combination, resulted in increased biomass, total nitrogen, and chlorophyll content in lettuce [18]. The application of algal extract and HA promotes root growth and nutrient uptake in Brassica napus, modulating the expression of the genes involved in nutrient uptake and translocation [19]. The addition of ANE and HA to creeping bent grass (Agrostis stolonifera L.) improved the overall physiological health of the bent grass that minimized the application of mineral fertilizers [20]. These reports suggest that the combination of different biostimulants are more effective in improving plant growth than the application of an individual one. In general, HAs improve soil fertility by transforming physical, chemical, and biological properties of soil, while ANE regulates physiological, biochemical, and molecular processes involved in plant growth regulation.

Post-harvest loss is a major issue in fruit and vegetable crops that cause significant economic loss to growers. Pre-harvest factors, such as light, temperature, nutrient availability, growth, soil conditions, and post-harvest factors, such as harvesting, handling, storage, and biotic stress, seriously affect post-harvest quality and result in reduced market value of produce [21-23]. Pre-harvest treatment of spinach with ANE improved the shelf life and reduced the fresh weight loss during storage, and also enhanced the phenolic content of spinach [24,25]. The application of commercial ANE enhanced the nutritional quality, such as total phenolics, flavonoids, and antioxidants, in spinach leaves [26]. Similarly, humic acid decreased the post-harvest weight loss of gerbera flowers [27]. Considering the properties and specific mechanisms of action of ANE and HA on plant growth, we hypothesized that the combination of ANE and HA will result in higher plant biostimulant activities and reduce post-harvest losses in lettuce and spinach, than when applied individually.

In this study, we evaluated the potential of HA and ANE, alone as well as in different combinations, for improving early growth of lettuce and spinach. The different combinations of HA and ANE were also evaluated for their effect in reducing post-harvest losses in these two crops.

\section{Materials and Methods}

\subsection{Seed Material}

Seeds of lettuce (Lactuca sativa L. cv. Paris Island Cos) and spinach (Spinacia oleracea L. cv. Sardinia) were purchased from Vessey Seeds (PEI, Canada) and were stored in the dark at $4{ }^{\circ} \mathrm{C}$.

\subsection{Preparation of Humic Acid and Seaweed Extract}

A commercial humic acid (HA) was purchased from Halifax Seed Company (Halifax, NS, Canada) and the extract of Ascophyllum nodosum (ANE) was a commercial formulation from Acadian Seaplants Limited (Dartmouth, NS, Canada). Two-percent stock solutions of HA and ANE were prepared in distilled water and stored at $4{ }^{\circ} \mathrm{C}$. Treatment solutions were prepared by mixing the stock solutions with distilled water. Treatments were used alone and in different combinations, as listed in Table S1. 


\subsection{Early Growth Assay}

Seeds of lettuce and spinach were planted $1.5 \mathrm{~cm}$ deep in plastic pots (size: $8.5 \times 5 \mathrm{~cm}$ diameter) containing PRO-MIX ${ }^{\circledR}$ (Premier Tech, QC, Canada). Each treatment had six replications and were arranged in a randomized complete block design on a glasshouse bench. Five days after germination, pots were irrigated once a week with $50 \mathrm{~mL}$ of different concentrations of ANE and HA alone and in combination for three weeks. Plants were irrigated with fertilizer solution $(1 \mathrm{~g} / \mathrm{L}$ of 20-20-20 nitrogen, phosphorous, and potassium (NPK)) at $50 \mathrm{~mL} /$ plant on the tenth and twentieth days post-germination. Pots were irrigated with water on alternate days or as required. Control plants were grown under identical conditions and irrigated with water and fertilizer throughout the experiment. The greenhouse conditions were maintained at $21 \pm 2{ }^{\circ} \mathrm{C}$ with a photoperiod of $12 / 12 \mathrm{~h}$ (day/night). After three weeks of treatment, growth parameters (fresh weight (FW), and dry weight (DW)) were recorded after drying plant biomass in an oven at $72{ }^{\circ} \mathrm{C}$ for $48 \mathrm{~h}$.). Percentage change in water content was calculated as $((\mathrm{FW}-\mathrm{DW}) / \mathrm{FW}) \times 100[28]$.

\subsection{Treatments}

Seeds of lettuce and spinach were planted $1.5 \mathrm{~cm}$ deep in large pots (size: $15.0 \times 10.5 \mathrm{~cm}$ ) containing PRO-MIX ${ }^{\circledR}$ (Premier Tech, QC, Canada). Each experiment was repeated three times. All treatments were arranged in a randomized complete block design in a greenhouse. Plants were treated once a week with combinations of ANE and HA at the rate of $100 \mathrm{~mL}$ per plant, for 4 weeks after germination. On the tenth and twentieth days post-germination, plants were irrigated with fertilizer containing $1 \mathrm{~g} / \mathrm{L}$ of 20-20-20 NPK. In order to maintain uniform moisture required for optimum growth, plants were irrigated with distilled water on alternate days of treatments. For this study, control plants were grown under the same conditions but treated with only distilled water. Similar to treatments, on the tenth and twentieth days post-germination, control plants were also irrigated with solution containing $1 \mathrm{~g} / \mathrm{L}$ of 20-20-20 NPK. The greenhouse was maintained at $21^{\circ} \mathrm{C}$ with a photoperiod of 12/12 h (day/night). After four weeks of treatment, plants were harvested to evaluate post-harvest shelf life under storage conditions.

\subsection{Sample Preparation and Post-Harvest Storage}

To study the effect of treatment of different combinations of ANE and HA on post-harvest storage, lettuce was harvested at 30 days while spinach was harvested at 35 days after planting. Plants were harvested with sharp scissors; fresh weight was recorded, and samples were then soaked in cold water to stabilize temperature. Then, the samples were placed in perforated plastic bags and stored in the dark in a controlled-environment storage room maintained at $0-4{ }^{\circ} \mathrm{C}$ and $95 \%$ relative humidity. For lettuce, samples were removed from storage on days 10 and 21 of storage. For spinach, leaves were removed on days 10, 21, and 28 of storage. At each time point, samples were assessed for color and turgor. Plant samples were cut into pieces, thoroughly mixed, and sub-samples were harvested immediately for analysis of chlorophyll and MDA (malondialdehyde) content. Remaining samples were flash-frozen in liquid nitrogen and stored at $-80^{\circ} \mathrm{C}$ for biochemical parameters.

\subsection{Weight Loss}

To determine the effect of different combinations of ANE and HA on weight loss during storage, plants were weighed on day 0 (i.e., day of harvesting) and were subsequently weighed at different time-points. The fresh weight recorded on the day of harvesting represent the yield of lettuce and spinach. Fresh weight loss was expressed as a percentage of the initial fresh weight, as described by Fan et al. [25]. Dry weight loss (DWL) during storage was recorded for each time point by drying plants in an oven maintained at $65^{\circ} \mathrm{C}$ for $48 \mathrm{~h}$ and expressed as $\mathrm{g} / 100 \mathrm{~g}$ fresh weight (FW). 


\subsection{Determination of Lipid Peroxidation}

The malondialdehyde (MDA) content was analyzed following a method described in Shukla et al. [29]. Fresh leaf samples (1 $\mathrm{g}$ of lettuce or $0.3 \mathrm{~g}$ of spinach) was homogenized in $15 \mathrm{~mL}$ of $80 \%$ $(\mathrm{v} / \mathrm{v})$ ethanol $(\mathrm{EtOH})$, followed by centrifugation at $3000 \times \mathrm{g}$ at $4{ }^{\circ} \mathrm{C}$ for $10 \mathrm{~min}$. The supernatant $(100 \mu \mathrm{L})$ and $900 \mu \mathrm{L}$ of distilled water were added to a test tube with $1 \mathrm{~mL}$ of either (i) -TBA (thiobarbituric acid) solution included with $20 \%(\mathrm{w} / \mathrm{v})$ trichloroacetic acid (TCA) and $0.01 \%(\mathrm{w} / \mathrm{v})$ butylated hydroxytoluene (BHT), or (ii) +TBA solution containing $0.65 \%(\mathrm{w} / \mathrm{v})$ TBA. The mixture was vortexed, heated at $95^{\circ} \mathrm{C}$ in a dry bath for $25 \mathrm{~min}$, cooled, and centrifuged at $3000 \times g$ for $10 \mathrm{~min}$. Absorbance was measured at 440, 532 , and $600 \mathrm{~nm}$. MDA equivalents were calculated using the following formula:

$$
\begin{gathered}
{\left[\left(\text { Abs }_{532+\mathrm{TBA}}\right)-\left(\text { Abs }_{600+\mathrm{TBA}}\right)-\left(\text { Abs }_{\left.\left.532-\mathrm{TBA}-\mathrm{Abs}_{600-\mathrm{TBA}}\right)\right]=\mathrm{A},}\right.\right.} \\
{\left[\left(\text { Abs }_{440+\mathrm{TBA}}-\mathrm{Abs}_{600-\mathrm{TBA}}\right) 0.0571\right]=\mathrm{B},} \\
\text { MDA equivalents }(\mathrm{nmol} / \mathrm{mL})=10^{6}[(\mathrm{~A}-\mathrm{B}) / 157,000] .
\end{gathered}
$$

\subsection{Determination of Pigments}

The effect of combinations of ANE and HA on pigments during post-harvest storage was evaluated as described by Ritchie [30]. Chlorophyll content was analyzed on days 10 and 21 post-harvest for lettuce and on days 10, 21, and 28 post-harvest for spinach in all treatments. Fresh tissue (1 $\mathrm{g}$ of lettuce and $0.3 \mathrm{~g}$ of spinach individually) was instantaneously ground using a mortar and pestle in $15 \mathrm{~mL}$ of cold methanol. Following extraction, the ground mixture was centrifuged at $10,000 \times g$ at $4{ }^{\circ} \mathrm{C}$ for $10 \mathrm{~min}$, and the pellet was re-extracted with $10 \mathrm{~mL}$ of cold methanol until all the color was removed. Extracts were combined, and total volume was made up to $25 \mathrm{~mL}$. Absorbance was measured at 652.4 and $665.2 \mathrm{~nm}$ using a spectrophotometer. The chlorophyll contents were calculated according to Lichtenthaler and Buschmann [31].

$$
\begin{aligned}
& C_{a}=16.72 A_{665.2}-9.16 A_{652.4} . \\
& C_{b}=34.09 A_{652.4}-15.28 A_{665.2} .
\end{aligned}
$$

\subsection{Determination of Total Ascorbic Acid}

Ascorbic acid was analyzed following the protocol developed by Fan et al. [24], with minor modifications whereby L-ascorbic acid was used as a standard. One gram of lettuce and $0.3 \mathrm{~g}$ of spinach were ground with $15 \mathrm{~mL}$ of ice-cold freshly-prepared $5 \%(\mathrm{w} / \mathrm{v}) \mathrm{m}$-phosphoric acid. Following the maceration, the mixture was centrifuged at $8000 \times g$ for $15 \mathrm{~min}$ at $4{ }^{\circ} \mathrm{C}$. Then $100 \mu \mathrm{L}$ of the supernatant was mixed with $500 \mu \mathrm{L}$ of $150 \mathrm{mM} \mathrm{KH}_{2} \mathrm{PO}_{4}$ buffer ( $\mathrm{pH} 7.4$ ), containing $5 \mathrm{mM}$ ethylene diamine tetra acetic acid (EDTA), and $100 \mu \mathrm{L} 10 \mathrm{mM}$ dithiothreitol (DTT) and incubated at room temperature for $50 \mathrm{~min}$. One hundred microliters of $0.5 \%(\mathrm{w} / \mathrm{v}) \mathrm{N}$-ethylmaleimide (NEM) was added to remove excess DTT. Reaction mixtures of $400 \mu \mathrm{L}$ of $10 \%$ (w/v) trichloroacetic acid (TCA), $400 \mu \mathrm{L}$ of $44 \%$ (v/v) o-phosphoric acid, $400 \mu \mathrm{L}$ of $4 \%$ (w/v) $\alpha$ - $\alpha 1$-dipyridyl, and $200 \mu \mathrm{L}$ of $30 \mathrm{~g} / \mathrm{L} \mathrm{FeCl}_{3}$ reagent were added in succession to obtain color. The reaction mixture was incubated at $40{ }^{\circ} \mathrm{C}$ for $60 \mathrm{~min}$ in a shaking incubator and absorbance was recorded at $525 \mathrm{~nm}$ using a spectrophotometer. Total ascorbic acid content was expressed as $\mu \mathrm{mol} / \mathrm{g} \mathrm{FW}$.

\subsection{Determination of Total Phenolic Content}

The total phenolic content was measured according to the method of Fan et al. [24]. One gram of lettuce and $0.3 \mathrm{~g}$ of spinach were macerated individually with $15 \mathrm{~mL}$ of $70 \% \mathrm{v} / \mathrm{v}$ methanol and centrifuged at $10,000 \times g$ for $10 \mathrm{~min}$. Extracts $(100 \mu \mathrm{L}$ each) were mixed with $2 \mathrm{~mL}$ of water and $100 \mu \mathrm{L}$ of $2 \mathrm{~N}$ Folin-Ciocalteu reagent and incubated for $10 \mathrm{~min}$. Following incubation, $300 \mu \mathrm{L}$ of $20 \%$ 
$(\mathrm{w} / \mathrm{v})$ sodium carbonate was added and the mixture was vortexed for a few seconds. The mixture was kept at room temperature in the dark for $2 \mathrm{~h}$ and the absorbance was measured at $765 \mathrm{~nm}$ using a spectrophotometer. A standard calibration curve $(0-9 \mu \mathrm{g} / \mathrm{mL})$ was plotted using gallic acid. Total phenolics was expressed as mg gallic acid equivalent (GAE)/g FW.

\subsection{Determination of Total Antioxidants}

The total antioxidant capacity of spinach leaves was determined by using the DPPH (2,2-diphenyl-1-picrylhydrazyl hydrate) assay following a method described by Brand-Williams et al. [32] with minor modifications. The antioxidants react with DPPH and it converts to 1,1-diphenyl-2-picryl hydrazine, forming discoloration (from deep violet to light yellow). One gram of lettuce and $0.3 \mathrm{~g}$ of spinach were flash-frozen individually in liquid nitrogen $(\mathrm{N})$ and stored at $-80{ }^{\circ} \mathrm{C}$. Each frozen sample was homogenized in $15 \mathrm{~mL}$ methanol $(\mathrm{MeOH})$ separately using a mortar and pestle. The supernatant was extracted by centrifuging at $10,000 \times g$ for $10 \mathrm{~min}$. The pellet was re-extracted with $10 \mathrm{~mL} \mathrm{MeOH}$, supernatants were combined, and the total volume was made up to $25 \mathrm{~mL}$. Fresh DPPH solution $(2850 \mu \mathrm{L}, 0.11 \mathrm{mM})$ was added to $100 \mu \mathrm{L}$ of each extract and incubated for $6 \mathrm{~h}$ at $22^{\circ} \mathrm{C}$. Absorbance was read at $517 \mathrm{~nm}$ against $\mathrm{MeOH}$ as a blank. The scavenging activity was calculated using the following equation: Inhibition $\%=[(\mathrm{Ab}-\mathrm{As}) / \mathrm{Ab}] 100$, where $\mathrm{Ab}$ is the absorption of the blank sample and As is the absorption in the presence of the test sample. The results were expressed in $\mu \mathrm{g}$ Trolox equivalents (TE)/g FW through comparison against a Trolox standard calibration curve $(0-20 \mathrm{ug} / \mathrm{mL})$.

\subsection{Statistical Analysis}

Each experiment was setup in a randomized complete block design and results were expressed as mean \pm standard error (SE). The ANOVA (analysis of variance) with two blocks was carried out using SAS v. 9.4 statistical software (SAS Institute Inc., Cary, NC, USA), with general linear model at a 95\% confidence interval and $5 \%$ level of significance. When the $p$-value was less than 0.05 , multiple means comparison was completed using the LSD (least significant difference) method to find means that were significantly different from others. The LSD was used due to uncontrollable sources (for example, temperature, humidity in the green house). The significantly different mean values were represented by different letters. Each experiment was performed in triplicate and each experimental unit had six plants, and for each response variable, the average of the eighteen values was used for ANOVA.

\section{Results}

\subsection{Ascophyllum nodosum Extract (ANE) and Humic Acid (HA) Improves Early Growth of Lettuce and Spinach}

\subsubsection{Lettuce}

ANE and HA treatments, either alone or in combination, showed significantly higher $(p \leq 0.0001)$ fresh weight of lettuce (Figure 1a). Treatment T2, 0.25\% ANE, showed higher fresh and dry weight, while $0.2 \% \mathrm{HA}$ (T3) showed a marginal increase in fresh and dry weights (Figure 1a,b). The combination of $0.25 \%$ ANE and $0.2 \% \mathrm{HA}$ (T8) had a significant growth-promoting effect in terms of fresh and dry weight, as compared to the control (Figure 1a,b). There was no significant difference in the percentage water content of the plants treated with other treatments, suggesting that ANE and HA significantly $(p \leq 0.0001)$ increases plant biomass (Figure 1c). The results presented here showed that the combination of $0.25 \%$ ANE and $0.2 \%$ HA was the most effective in improving the biomass of lettuce, as compared to the control, $0.25 \%$ (T2), and 0.2\% HA (T3) alone (Figure 1a-c). 

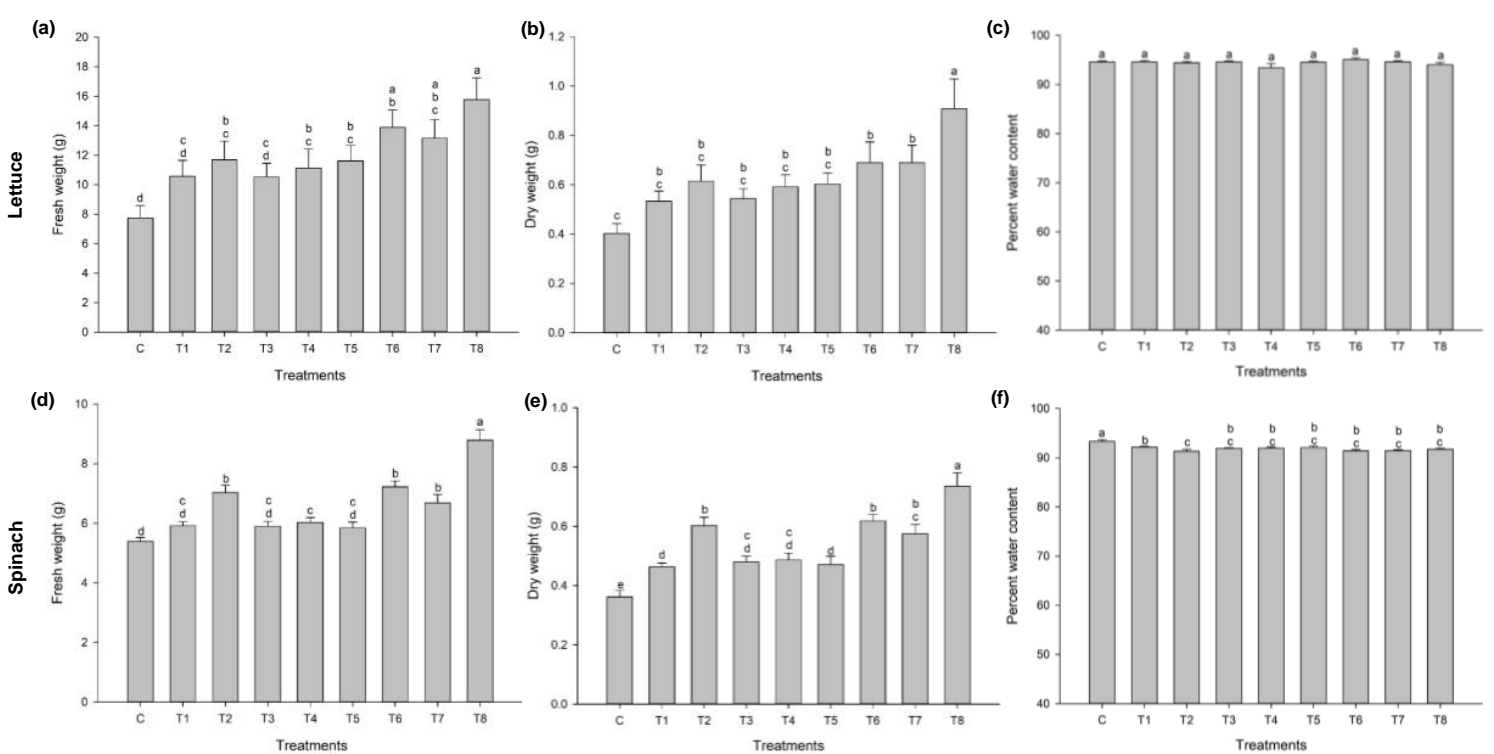

Figure 1. Effect of Ascophyllum nodosum extract (ANE) and Humic acid (HA) on fresh weight, dry weight, and percent water content of $(\mathbf{a}-\mathbf{c})$ lettuce and $(\mathbf{d}-\mathbf{f})$ spinach seedlings. Different combinations of ANE and HA were used as follows: C (control), T1 (0.1\% ANE), T2 (0.25\% ANE), T3 (0.2\% HA), T4 (0.4\% HA), T5 (0.1\% ANE + 0.2\% HA), T6 (0.1\% ANE + 0.4\% HA), T7 (0.25\% ANE + 0.4\% HA), and $\mathrm{T} 8(0.25 \% \mathrm{ANE}+0.2 \% \mathrm{HA})$. Each experiment was performed in triplicate, and each experimental unit had six plants. The average of the eighteen values were presented as mean $\pm \mathrm{SE}$ and means represented by same letters were not significantly different at $p \leq 0.05$.

\subsubsection{Spinach}

Twenty-one days' post-treatment, $0.25 \%$ ANE (T2), 0.1\% ANE + 0.4\% HA (T6), and 0.25\% ANE $+0.2 \%$ HA (T8) determined a significant increase in plant fresh and dry weights (Figure 1a,b). The application of $0.25 \%$ ANE and $0.2 \%$ HA (T8) had an additive effect on the growth-promotion of spinach in terms of both fresh and dry weights as compared to the control (Figure 1a,b). Percentage water content in ANE and HA treated plants was significantly reduced as compared to the control in all treatments (Figure 1c).

\subsection{Effect of Pre-Harvest Treatment of Ascophyllum nodosum Extract (ANE) and Humic Acid (HA) on Yield and Post-Harvest Weight-Loss}

\subsubsection{Lettuce}

Based on the early growth experiment, $0.1 \%$ ANE (T1), 0.25\% ANE (T2), 0.2\% HA (T3), $0.4 \%$ HA (T4), $0.1 \%$ ANE + 0.4\% HA (T6), and 0.25\% ANE + 0.2\% HA (T8) were evaluated for their efficacy in reducing post-harvest losses. The effect of ANE, HA, and ANE + HA on yield of lettuce was evaluated after 30 days of plant growth (Figure S1). All of the treatments showed an increase in fresh weight of lettuce. The combination of ANE and HA (T6, 0.1\% ANE + 0.2\% HA) showed the maximum increase in fresh weight of lettuce plants, as compared to the other treatments and control (Figure S1).

The effect of ANE, HA, and ANE + HA on post-harvest loss of fresh weight of lettuce plants was studied after 10 and 21 days of storage (Figure 2). All treatments, including the control, showed a decrease in post-harvest weight with the increase in storage time. A significant reduction in weight loss $(59.5 \%$ on day 10 and $50.5 \%$ on day 21$)$ was observed in lettuce plants treated with $\mathrm{T} 8(0.25 \%$ ANE + $0.2 \% \mathrm{HA})$ during the storage period (Figure 2a,b). Similarly, T3 (0.2\% HA) and T2 (0.25\% ANE) showed significant reductions in weight loss after 21 days of post-harvest storage of lettuce, as compared to the controls (Figure 2a,b). ANE + HA significantly reduced the fresh weight loss of stored produce when compared with the control. In the control lettuce plants, the $24.3 \%$ reduction in DMC was observed after 21 days of storage (Figure 2c). The most effective treatment, T8 $(0.25 \%$ ANE $+0.2 \% \mathrm{HA})$, reduced 
the lettuce DMC by $0.3 \%$, which is significantly less than the control after 21 days of storage (Figure 2c). These results suggest that pre-harvest treatment of lettuce leaves with combination ANE and HA had a more profound effect on the post-harvest storage of lettuce, as compared to the individual concentration as well as the control (Figure 2).

(a)

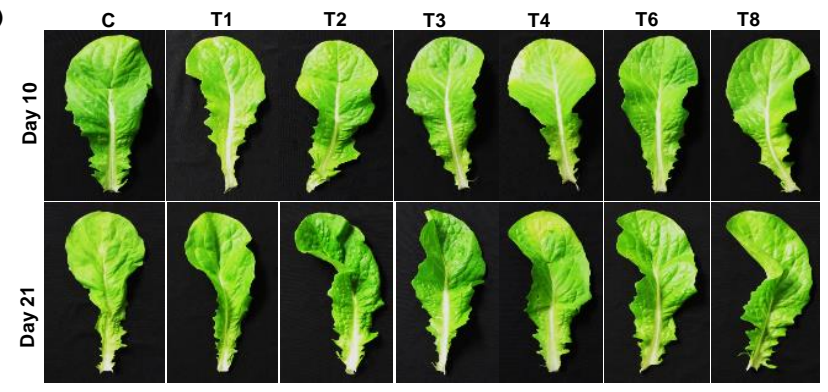

(b)

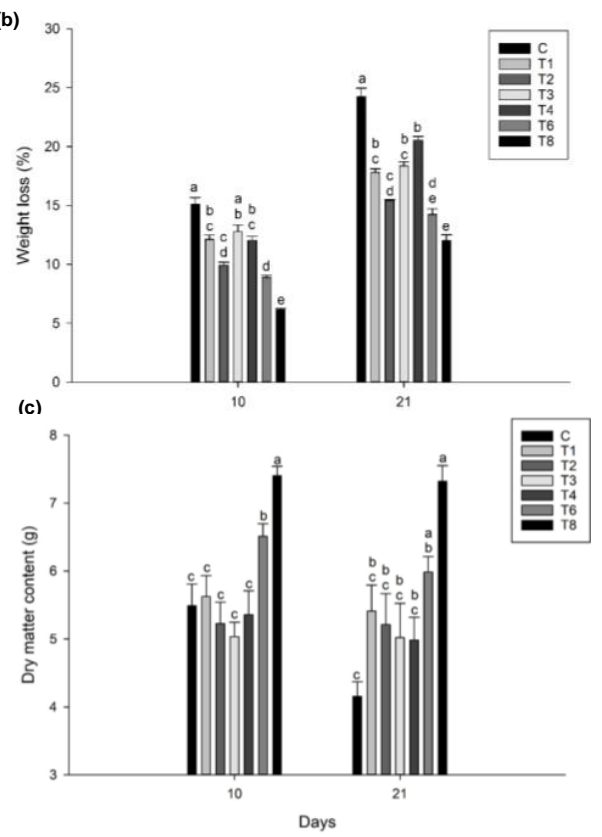

Figure 2. Effect of pretreatment of ANE and HA on fresh weight loss and dry matter content during postharvest storage of lettuce. (a) This figure represents leaves of lettuce treated with different concentrations of ANE and HA alone, and their combinations held over 10 and 21 days of storage at $0-4{ }^{\circ} \mathrm{C}$ in the dark with relative humidity $(\mathrm{RH}) \geq 95 \%$. The post-harvest (b) fresh weight loss and (c) dry matter content (DMC) of lettuce leaves after 10 and 21 days of post-harvest storage at $0-4{ }^{\circ} \mathrm{C}$ in the dark with $\mathrm{RH} \geq 95 \%$. Different combinations of ANE and HA used for preharvest treatment were as follows: C (control), T1 (0.1\% ANE), T2 (0.25\% ANE), T3 (0.2\% HA), T4 (0.4\% HA), T6 (0.1\% ANE + $0.4 \% \mathrm{HA})$, and $\mathrm{T} 8(0.25 \% \mathrm{ANE}+0.2 \% \mathrm{HA})$. Each experiment was performed in triplicate, and each experimental unit had six plants. The average of the eighteen values were presented as mean $\pm \mathrm{SE}$ and means represented by same letters were not significantly different at $p \leq 0.05$.

\subsubsection{Spinach}

Spinach plants treated with ANE, HA, and ANE + HA showed an increase in the fresh weight after 35 days. T2 (0.25\% ANE), T3 (0.2\% HA), T4 (0.4\% HA), T6 (0.1\% ANE + 0.2\% HA), and T8 $(0.25 \%$ ANE $+0.2 \% \mathrm{HA})$ significantly improved the fresh weight of spinach (Figure S2).

The pre-harvest root drench of spinach with ANE, HA, and their combinations showed a significant reduction in fresh weight loss of spinach during the 28-day storage period compared to the control $(p \leq 0.05)$ (Figure $3 a, b)$. As expected there was a gradual loss of the fresh weight of spinach over the period of storage. The treatments $0.25 \%$ ANE (T2) and $0.2 \%$ HA (T3) showed significant reductions in fresh weight loss during post-harvest storage. However, treatment consisting of ANE $(0.25 \%)+\mathrm{HA}$ $(0.2 \%)$ (T8) showed $49.2 \%, 45.7 \%$, and $39.3 \%$ reduction in fresh weight loss on days 14,21 , and 28 of the storage period, respectively, which was statistically significant (Figure 3b). Similarly, T6 (0.1\% ANE + $0.2 \% \mathrm{HA}$ ) reduced the fresh weight loss on the same days by $47.6 \%, 39.5 \%$, and $37.4 \%$, respectively, compared to the control (Figure $3 b)$. The higher dry matter content (DMC) of spinach was observed in all treatments, as compared to the controls, but the DMC decreased as the duration of the storage period increased. The highest reduction in DMC was observed by $32 \%$ and $38.34 \%$ in the spinach plants treated with water (C) and $0.1 \%$ ANE (T1), respectively, after 28 days of storage. However, the lowest reduction in DMC of spinach plants during storage of 28 days was observed in T4 $(0.4 \% \mathrm{HA})$, 
T6 $(0.1 \%$ ANE $+0.4 \% \mathrm{HA})$, and T8 $(0.25 \%$ ANE $+0.2 \% \mathrm{HA})$ (Figure $3 \mathrm{c})$. These results suggest that combination of ANE and HA effectively reduced the loss of spinach during post-harvest storage, as compared to the control or ANE and HA alone (Figure 3).

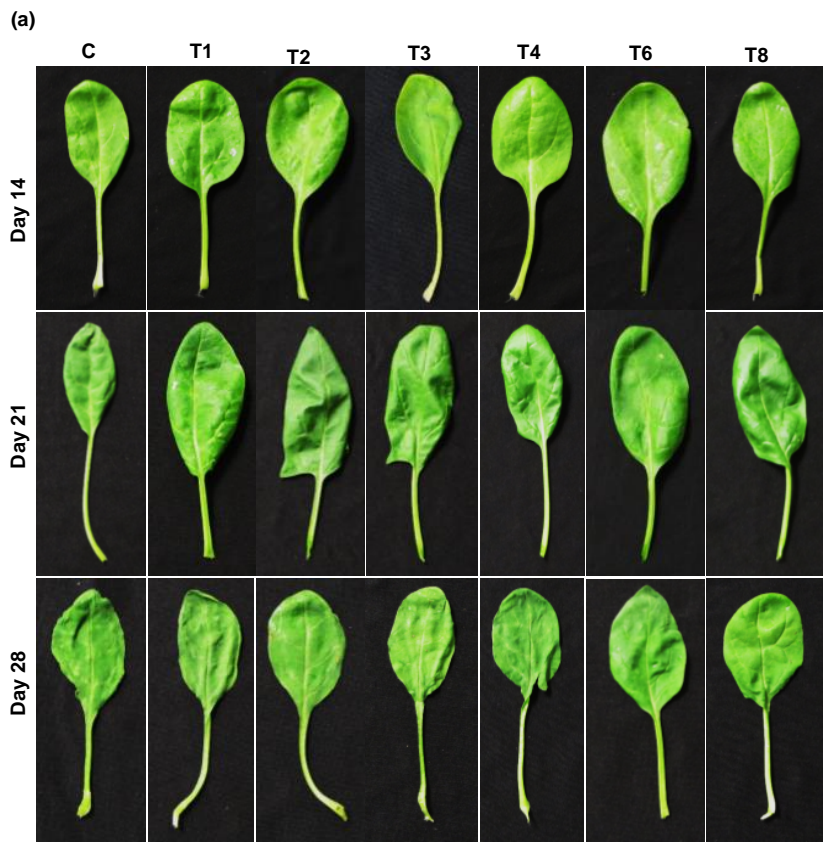

(b)

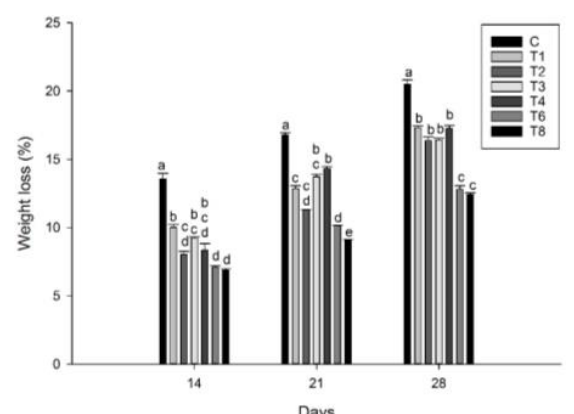

(c)

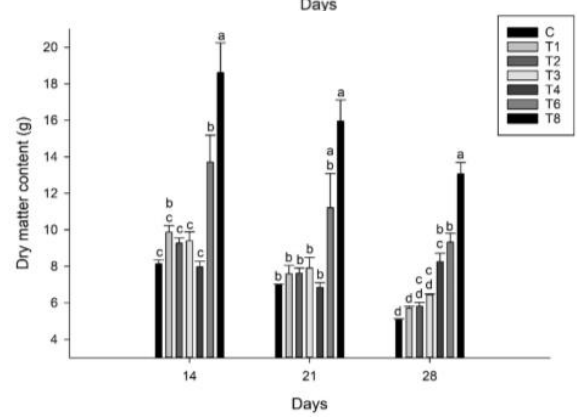

Figure 3. Effect of pretreatment of ANE and HA on fresh weight loss and dry matter content during postharvest storage of spinach. (a) This figure represents leaves of spinach treated with different concentrations of ANE and HA, alone and their combinations, over 14, 21, and 28 days of storage at $0-4{ }^{\circ} \mathrm{C}$ in the dark with $\mathrm{RH} \geq 95 \%$. The postharvest (b) fresh weight loss and (c) dry matter content (DMC) of spinach leaves after 14, 21, and 28 days of post-harvest storage at $0-4{ }^{\circ} \mathrm{C}$ in the dark with $\mathrm{RH} \geq 95 \%$. Different combinations of ANE and HA used for preharvest treatment were as follows: C (control), T1 (0.1\% ANE), T2 (0.25\% ANE), T3 (0.2\% HA), T4 (0.4\% HA), T6 (0.1\% ANE + 0.4\% HA), and T8 $(0.25 \%$ ANE $+0.2 \% \mathrm{HA})$. Each experiment was performed in triplicate, and each experimental unit had six plants. The average of the eighteen values were presented as mean $\pm \mathrm{SE}$ and means represented by same letters were not significantly different at $p \leq 0.05$.

3.3. Ascophyllum nodosum Extract (ANE) and Humic Acid (HA) Retains Pigmentation during Post-Harvest Storage of Lettuce and Spinach

\subsubsection{Lettuce}

ANE, HA, and ANE + HA treatments showed no significant effect on chlorophyll a content of lettuce on day 10 of the storage period (Figure 4). Lettuce plants treated with T8 (0.25\% ANE + 0.2 \% HA) showed significantly higher chlorophyll a content of lettuce leaves stored for 21 days post-harvest, as compared to the control, 0.25\% ANE (T2), and $0.2 \%$ HA (T3) alone (Figure 4a). The treatments showed no significant effect on the chlorophyll b content of lettuce throughout the storage period (Figure 4b).

\subsubsection{Spinach}

The pre-harvest root drench treatment of spinach plants with ANE, HA, and ANE + HA showed significantly higher chlorophyll a content of spinach on day 14 of the storage period (Figure 5a). However, no significant effect was observed on days 21 and 28. Chlorophyll b was numerically higher in all treatments on days 21 and 28 of post-harvest storage (Figure 5b). Overall, there was no significant effect of treatments on chlorophyll a or chlorophyll b in spinach on days 21 or 28 of post-harvest storage. 
(a)

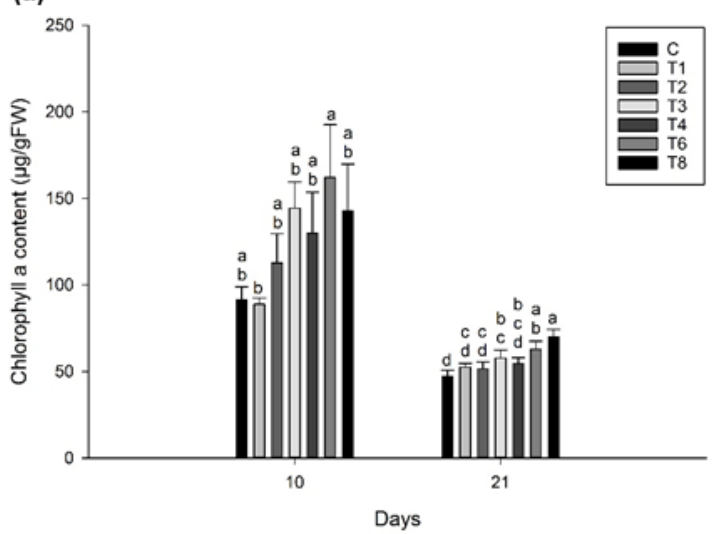

(b)

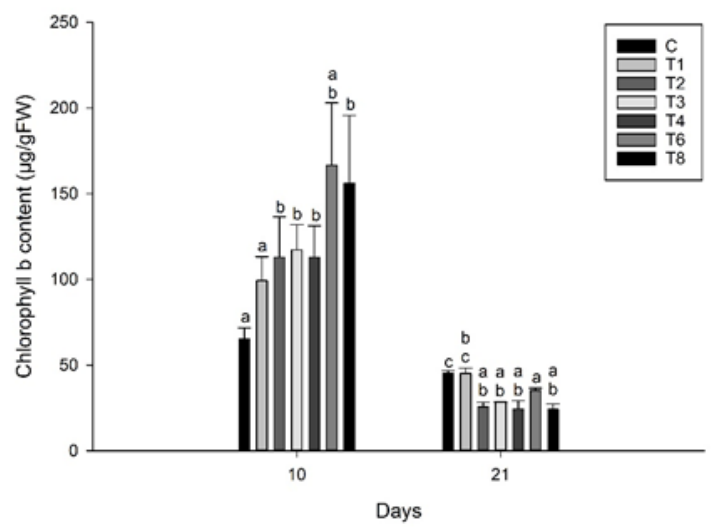

Figure 4. Effect of pretreatment of ANE and HA on the chlorophyll content of leaves of lettuce stored after harvest. The effect of different concentrations of ANE, HA, and ANE + HA on the (a) chlorophyll a and (b) chlorophyll b content of leaves of lettuce stored for 10 and 21 days at $0-4{ }^{\circ} \mathrm{C}$ in the dark with $\mathrm{RH} \geq 95 \%$. Different combinations of ANE and HA used for preharvest treatment were as follows: C (control), T1 (0.1\% ANE), T2 (0.25\% ANE), T3 (0.2\% HA), T4 (0.4\% HA), T6 (0.1\% ANE + 0.4\% HA), andT8 $(0.25 \%$ ANE + $0.2 \%$ HA). Each experiment was performed in triplicate, and each experimental unit had six plants. The average of the eighteen values were presented as mean $\pm \mathrm{SE}$ and means represented by same letters were not significantly different at $p \leq 0.05$.

(a)

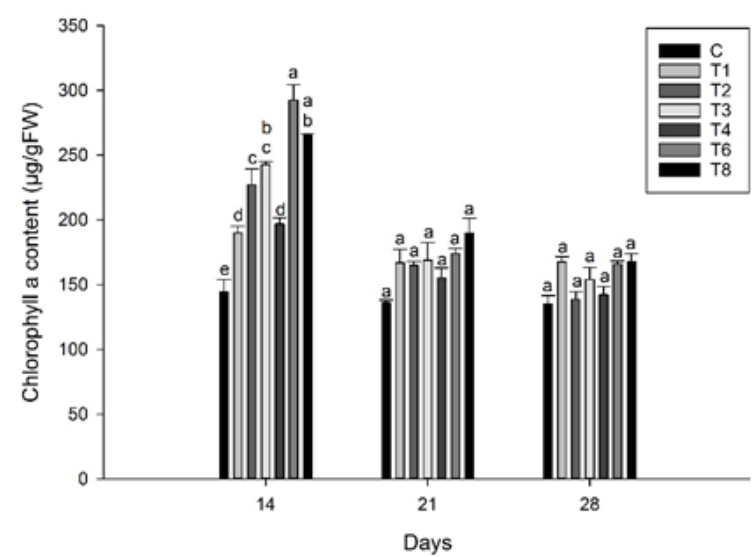

(b)

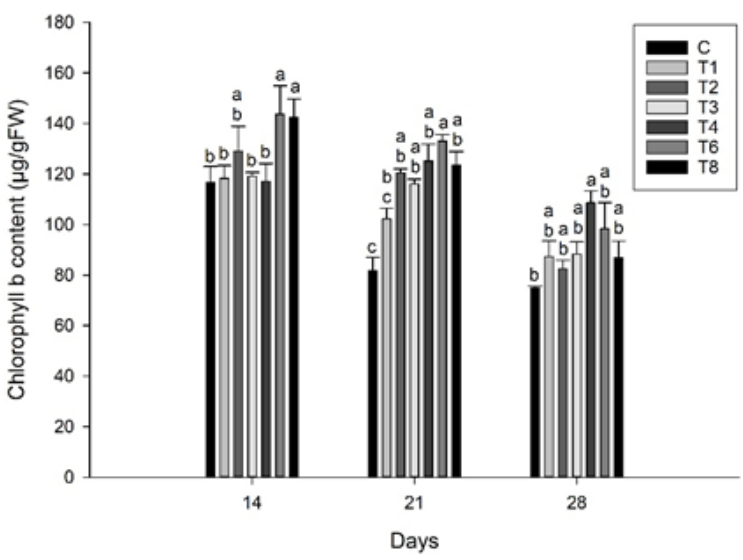

Figure 5. Effect of pretreatment of ANE and HA on the chlorophyll content of leaves of spinach stored after harvest. The effect of different concentrations of ANE, HA, and ANE + HA on the (a) chlorophyll a and (b) chlorophyll b contents of leaves of spinach stored for 14,21 , and 28 days at $0-4{ }^{\circ} \mathrm{C}$ in the dark with $\mathrm{RH} \geq 95 \%$. Different combinations of ANE and HA used for preharvest treatment were as follows: C (control), T1 (0.1\% ANE), T2 (0.25\% ANE), T3 (0.2\% HA), T4 (0.4\% HA), T6 (0.1\% ANE + $0.4 \% \mathrm{HA})$, and T8 (0.25\% ANE + 0.2\% HA). Each experiment was performed in triplicate, and each experimental unit had six plants. The average of the eighteen values were presented as mean $\pm \mathrm{SE}$ and means represented by same letters were not significantly different at $p \leq 0.05$.

\subsection{Ascophyllum nodosum Extract (ANE) and Humic Acid (HA) Reduces Lipid Peroxidation during} Post-Harvest Storage of Lettuce and Spinach

\subsubsection{Lettuce}

MDA (malondialdehyde) is a biomarker and a secondary product formed during lipid peroxidation and can also be an indicator of oxidative stress. Lipid peroxidation increased in lettuce plants during post-harvest storage (Figure 6a). MDA content was reduced significantly in plants treated with T8 
$(0.25 \%$ ANE $+0.2 \%$ HA) and T6 (0.1\% ANE + 0.4\% HA) on day 10 compared with the control (72.6\% and 78.7\%, respectively). Increased MDA content in all treatments was shown on day 21 compared to day 10, but a significant reduction in MDA content was observed in plants treated with $\mathrm{T} 1$ (0.1\% ANE), T6 (0.1\% ANE + 0.4\% HA) and T8 (0.25\% ANE + 0.2\% HA), compared with the control (Figure 6a). The maximum reduction in lipid peroxidation (39\%) was observed in plants treated with $0.25 \%$ ANE + 0.2\% HA, as compared to the plants treated with $0.25 \%$ ANE (T2) and $0.2 \%$ HA (T3) alone (Figure 6a).
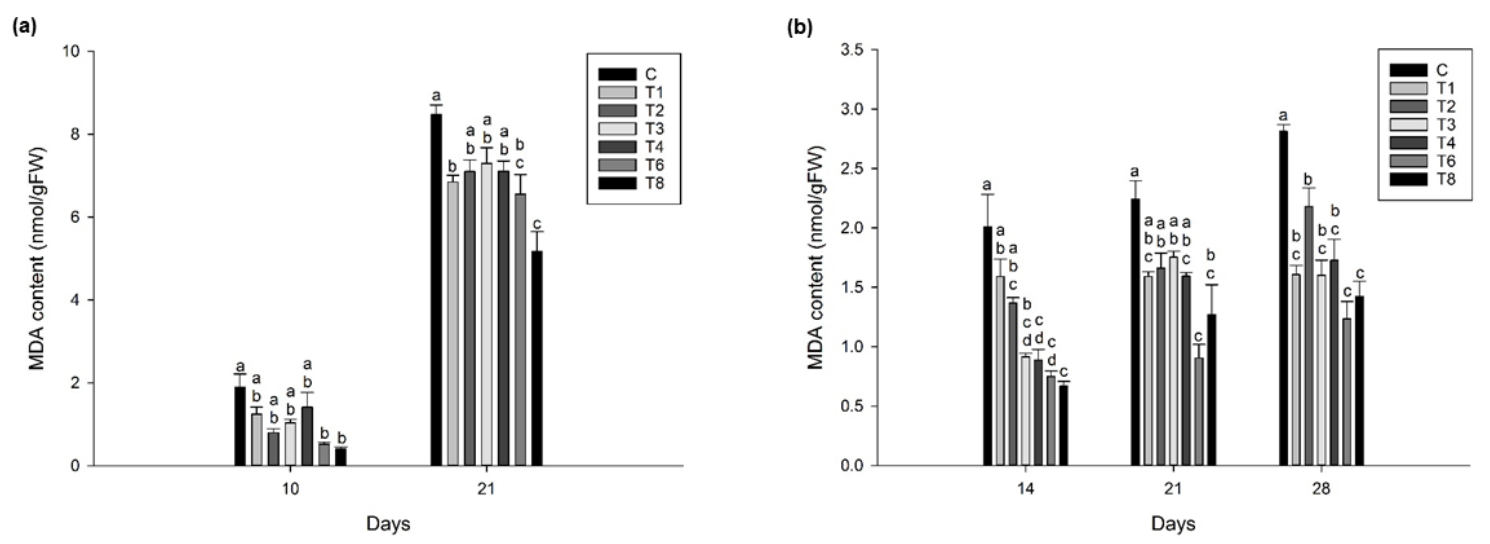

Figure 6. Effect of pretreatment of ANE and HA on the malondialdehyde (MDA) content in leaves of lettuce and spinach stored after harvest. (a) MDA content of leaves of lettuce stored at $0-4{ }^{\circ} \mathrm{C}$ in the dark with $\mathrm{RH} \geq 95 \%$ for 10 and 21 days, treated with different concentrations of ANE, HA, and ANE + HA before harvest. (b) MDA content of leaves of spinach stored at $0-4{ }^{\circ} \mathrm{C}$ in the dark with $\mathrm{RH} \geq 95 \%$ for 14, 21, and 28 days, treated with different concentrations of ANE, HA, and ANE + HA before harvest. Different combinations of ANE and HA used for preharvest treatment were as follows: $\mathrm{C}$ (control), T1 (0.1\% ANE), T2 (0.25\% ANE), T3 (0.2\% HA), T4 (0.4\% HA), T6 (0.1\% ANE + 0.4\% HA), and T8 $(0.25 \%$ ANE $+0.2 \% \mathrm{HA})$. Each experiment was performed in triplicate, and each experimental unit had six plants. The average of the eighteen values were presented as mean $\pm \mathrm{SE}$ and means represented by same letters were not significantly different at $p \leq 0.05$.

\subsubsection{Spinach}

In spinach, ANE, HA, and ANE + HA treatments moderately reduced peroxidation on days 14, 21 , and 28 compared with the control. The gradual increase in lipid peroxidation was observed in all the treated and untreated plants, but T6 (0.1\% ANE + 0.4\% HA) and T8 (0.25\% ANE + 0.2\% HA) showed a significant reduction was observed in lipid peroxidation during the whole storage period, according to Figure $6 \mathrm{~b}$.

\subsection{Ascophyllum nodosum Extract (ANE) and Humic Acid (HA) Showed Higher Total Ascorbic Acid, Phenolics, and Antioxidant Content in Lettuce and Spinach during Post-Harvest Storage}

\subsubsection{Lettuce}

Total ascorbate content in lettuce plants on day 10 of the storage period was significantly higher in T6 (0.1\% ANE + $0.4 \%$ HA) and T8 (0.25\% ANE + 0.2\% HA) compared to the control (Figure 7a). A rapid decrease in ascorbates was observed on day 21 without any significant differences between treatments. Total ascorbates reduced from 30.7 to $9.2 \mu \mathrm{mol} / \mathrm{g}$ FW (Figure 7a). Overall, ANE-, HA-, and ANE + HA-treated plants showed significantly higher ascorbic content on day 21 compared with untreated plants. The pre-harvest treatment with ANE, HA, and ANE + HA resulted in significantly higher $(p \leq 0.01)$ phenolics content in T2 $(0.25 \%$ ANE), T6 (0.1\% ANE + 0.4\% HA), and T8 (0.25\% ANE + $0.2 \% \mathrm{HA}$ ) on day 10 of the storage compared to the control (Figure $7 \mathrm{~b}$ ). Phenolics content was less in all treatments on day 21 compared to day 10 , though plants treated with $\mathrm{T} 8(0.25 \% \mathrm{ANE}+0.2 \% \mathrm{HA})$ and 
T2 (0.25\% ANE) had 0.7- and 0.5-fold increase in phenolics content, respectively, on day 21 compared with the control (Figure $7 \mathrm{~b})$. Overall, lettuce plants treated with T8 $(0.25 \% \mathrm{ANE}+0.2 \% \mathrm{HA})$ and T2 ( $0.25 \%$ ANE) had significantly higher phenolics content after the 21-day storage period compared with the control and other treatments. The pre-harvest treatment of lettuce with ANE, HA, and ANE + HA significantly $(p \leq 0.025)$ increased the total antioxidant capacity of lettuce during the 21-day storage period compared with the control (Figure 7c). All treated and untreated lettuce plants' total antioxidant capacity reduced as the duration of the storage period increased. However, the treated plants showed increased antioxidants on days 10 and 21 of the storage period compared to the control (Figure 7c). These results suggest that the pre-harvest application of the combination of ANE and HA significantly increased the total antioxidant capacity of lettuce during 21 days in storage (Figure 7c)
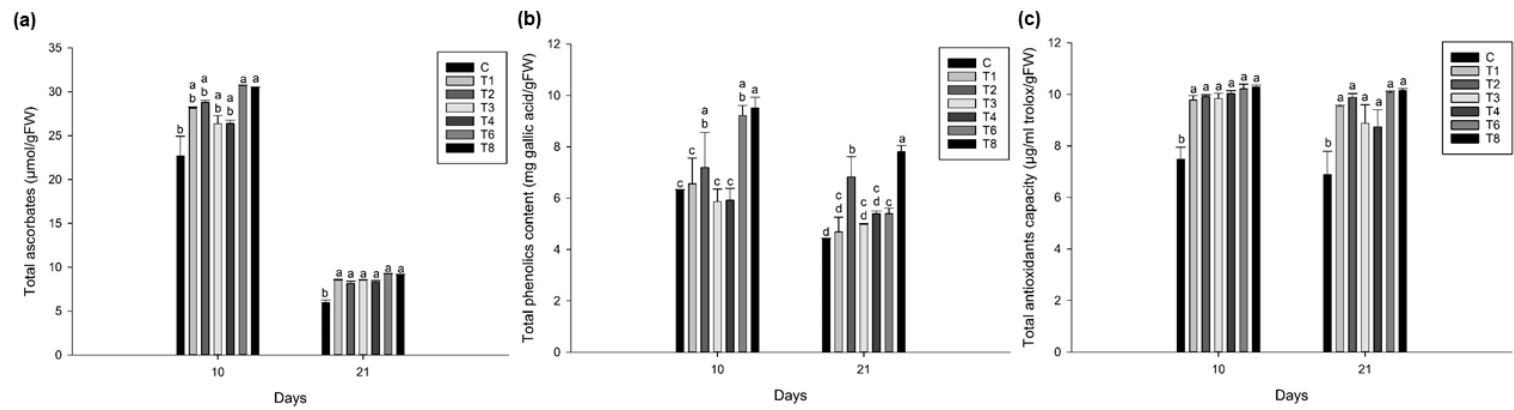

Figure 7. Effect of the preharvest treatment of ANE, HA, and different combinations of ANE + HA on (a) total ascorbates content, (b) total phenolics content, and (c) total antioxidant capacity of leaves of lettuce stored at $0-4{ }^{\circ} \mathrm{C}$ in the dark with $\mathrm{RH} \geq 95 \%$ for 10 and 21 days after harvest. Different combinations of ANE and HA used for preharvest treatment were as follows: C (control), T1 (0.1\% ANE), T2 (0.25\% ANE), T3 (0.2\% HA), T4 (0.4\% HA), T6 (0.1\% ANE + 0.4\% HA), and T8 (0.25\% ANE + $0.2 \%$ HA). Each experiment was performed in triplicate, and each experimental unit had six plants. The average of the eighteen values were presented as mean $\pm \mathrm{SE}$ and means represented by same letters were not significantly different at $p \leq 0.05$.

\subsubsection{Spinach}

A 1.4- and 2.5-fold increase in ascorbates content was observed in spinach plants treated with T6 $(0.1 \%$ ANE $+0.4 \% \mathrm{HA})$ and T8 $(0.25 \%$ ANE + $0.2 \% \mathrm{HA})$, respectively, compared with the control, on day 14 of the storage period. The gradual decrease in total ascorbates was observed throughout the duration of the storage period; however, plants treated with $\mathrm{T} 6(0.1 \% \mathrm{ANE}+0.4 \% \mathrm{HA})$ and $\mathrm{T} 8(0.25 \% \mathrm{ANE}+$ $0.2 \% \mathrm{HA}$ ) showed significantly higher amounts of ascorbates compared with the control (Figure $8 \mathrm{a}$ ). On day 14 , a significantly higher phenolic content was recorded in plants treated with T6 $(0.1 \%$ ANE $+0.4 \% \mathrm{HA})(74 \%)$ and T8 (0.25\% ANE + 0.2\% HA) (112.4\%), compared with the control $(p \leq 0.001)$, whereas a rapid decline in phenolic content on day 21 was shown with no significant difference between treatments (Figure $8 \mathrm{~b}$ ). Prolonged storage of lettuce up to 28 days showed significantly higher phenolic content in plants treated with T6 $(0.1 \%$ ANE $+0.4 \% \mathrm{HA})$ and T8 $(0.25 \%$ ANE $+0.2 \% \mathrm{HA})$ (Figure $8 \mathrm{~b})$. The pre-harvest treatment with ANE, HA, and their combinations significantly increased the total antioxidant capacity in spinach throughout the duration of the 28-day storage period $(p \leq 0.0013)$. Treated and untreated spinach plants exhibited a reduction in total antioxidants as the duration of the storage period increased (Figure 8c). However, plants treated with T6 (ANE 0.1\% + HA 0.4\%) and T8 (ANE $0.25 \%+$ HA $0.2 \%$ ) recorded significantly higher antioxidants on days 14, 21, and 28, compared to the other treatments and control. The results suggest that the pre-harvest application with $0.25 \%$ ANE $+0.2 \%$ HA increased the total antioxidant capacity of lettuce throughout the storage period (Figure $8 \mathrm{c}$ ). 

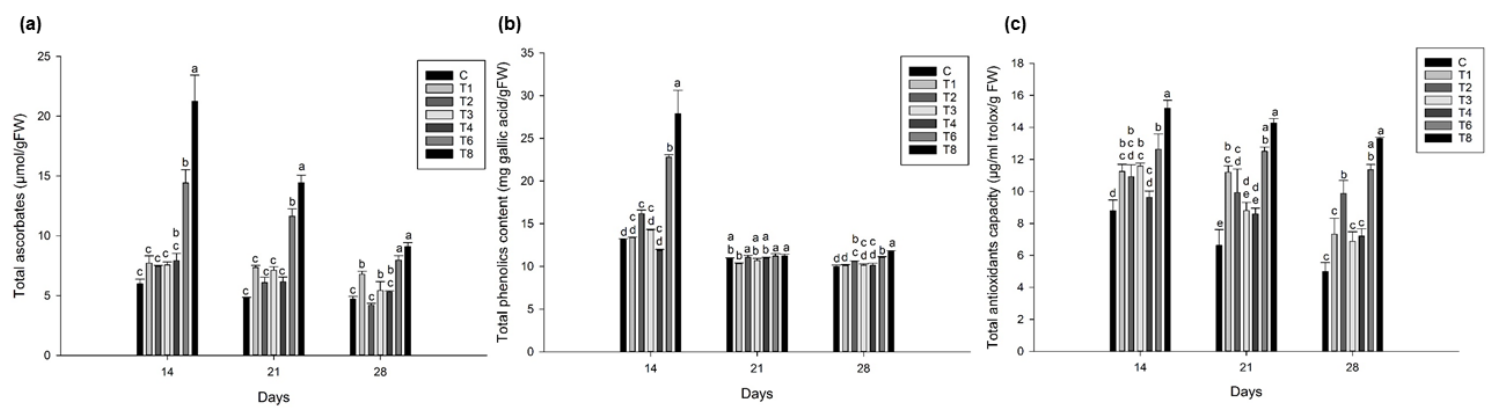

Figure 8. Effect of the preharvest treatment of ANE, HA, and different combinations of ANE + HA on (a) total ascorbates content, (b) total phenolics content, and (c) total antioxidant capacity of leaves of spinach stored at $0-4{ }^{\circ} \mathrm{C}$ in the dark with $\mathrm{RH} \geq 95 \%$ for 14,21 , and 28 days after harvest. Different combinations of ANE and HA used for preharvest treatment were as follows: $\mathrm{C}$ (control), T1 (0.1\% ANE), T2 (0.25\% ANE), T3 (0.2\% HA), T4 (0.4\% HA), T6 (0.1\% ANE + 0.4\% HA), and T8 (0.25\% ANE + $0.2 \%$ HA). Each experiment was performed in triplicate, and each experimental unit had six plants. The average of the eighteen values were presented as mean $\pm \mathrm{SE}$ and means represented by same letters were not significantly different at $p \leq 0.05$.

\section{Discussion}

In this study, we evaluated the effect of pre-harvest treatment of combinations of ANE and HA in reducing post-harvest losses during storage of lettuce and spinach. Root drench with a combination of ANE and HA stimulated early growth of lettuce and spinach, the stimulatory effect of the combination was higher than individual treatments. The fresh weight and dry weight was significantly higher in the spinach and lettuce treated with the combination of $0.25 \%$ ANE and $0.2 \%$ HA. The role of ANE in improving plant growth is well documented in scientific literature $[9,12,33]$. Humic acid has plant growth-promoting activities like nutrient uptake by chelating metal ions, protein synthesis, oxidative phosphorylation, and photosynthesis [34]. Therefore, the enhanced effect of the combination of ANE and HA might be due to the additive or synergistic effect of ANE and HA. Similarly, in an earlier study, Billard et al. [19] showed that application of Ascophyllum nodosum extract (AZAL5) and humic acid (HA7) improved plant biomass and nutrient uptake. Overall, the findings of this study suggest that the combined application of ANE and HA improves early growth of spinach and lettuce.

The root drench application of different concentrations of ANE and HA, and their combinations, were tested for their effect on reducing post-harvest losses in lettuce and spinach. Fresh weight loss and dry matter content are important parameters of produce during storage, as these characteristics decide the market value of the commodity [35-37]. Pre-harvest root drench treatment with $0.25 \%$ ANE $+0.2 \%$ HA showed significantly reduced fresh weight loss of lettuce and spinach during the storage period. Dry matter loss of lettuce and spinach treated with $0.25 \%$ ANE + 0.2\% HA during storage was significantly reduced as compared to the controls. This might be due to the enhanced nutrient uptake by application of ANE [9,38], and the addition of humic acid with ANE might further enhance the nutrient uptake of the plant through its chelation effects [15]. Fan et al. [25] also showed that pre-treatment application of $0.1 \%$ ANE reduced the weight loss of spinach during storage, but in the present study we showed the combination of both biostimulants were more effective in reducing the post-harvest losses, as compared to when they were used alone. The total chlorophyll content was reduced during post-harvest storage [39], but was higher in lettuce and spinach treated with ANE and HA and their combinations. Similarly, Fan et al. [25] also showed pre-harvest treatment of ANE increased total chlorophyll content in the spinach during post-harvest storage. Post-harvest-induced senescence lead to the degradation of chlorophyll and was reduced by the application of cytokinins [40]. Both ANE and HA possess cytokinin-like activities [9,41,42]. Thus, the cytokinin-like properties present in both the biostimulants prevents the degradation of chlorophyll during post-harvest storage. Taken together, these results suggest that the combination of both biostimulants effectively restores the visual 
marketable parameters of lettuce and spinach for a longer duration, as compared to the individual treatment as well as control.

Previous studies have shown that post-harvest storage causes biophysical changes in membrane lipids by enzymatic and non-enzymatic lipid peroxidation, and causes increased ion leakage and deterioration of plant tissue [25,43-46]. MDA, produced as a byproduct of lipid peroxidation, is used as a biomarker of oxidative damage [28]. The application of ANE reduces lipid peroxidation in spinach during post-harvest storage [25], which was in concurrence with the results reported in this study. Although the MDA content was reduced in all the treatments, the combination of ANE and HA more effectively reduced MDA content of lettuce and spinach during post-harvest storage, as compared to the individual treatments of ANE and HA. These results suggest that pre-harvest treatment with the combination of ANE and HA significantly reduces oxidative damage during post-harvest storage, through increased biosynthesis of antioxidative enzymes and compounds such as phenolics and flavonoids $[24,25,47]$. The pre-harvest treatment with $A$. nodosum extract showed higher antioxidant and ascorbate content in spinach [22,23]. Ascorbates are important antioxidants that rapidly degrade during storage in leafy vegetables [48]. During post-harvest storage, the ascorbate is oxidized to dehydroascorbic acid (DHA) by ascorbate oxidase [48]. The results presented in this study showed that treatment with the combination of ANE and HA significantly reduced the degradation of ascorbate in lettuce and spinach during storage. These results were further supported by the higher phenolics content and antioxidant capacity of plants treated with combination of ANE and HA. Thus, the plausible reason behind the synergistic effect of ANE and HA is that ANE induces biosynthesis of antioxidants during storage, while $\mathrm{HA}$ chelates the metal ions $(\mathrm{Fe} 3+, \mathrm{Cu} 2+, \mathrm{Ag}+)$ needed for the activity of ascorbate oxidase [42,49]. Overall, treatment with the combination of ANE and HA improves the antioxidant capacity of lettuce and spinach, which in turn reduces the lipid peroxidation caused by ROS and improves the quality of lettuce and spinach during post-harvest storage.

Although mechanisms of action of ANE and HA is not well understood, we speculate that plant hormone-like substances, osmolytes, and nutrients present in the biostimulants are promoting these physiological responses based on prior investigations.

\section{Conclusions}

The optimization of the different concentrations of preharvest application of ANE and HA offers a sustainable strategy for reducing post-harvest losses of leafy vegetables. In this study, the pre-harvest application of the combination of ANE $(0.25 \%)$ and HA $(0.2 \%)$ showed reduced loss of lettuce and spinach during post-harvest storage. Overall, an additive effect of the combination of ANE and HA was observed on the early growth and reduced post-harvest loss of lettuce and spinach. The results presented in this study showed that ANE and HA, as biostimulants, exhibit high potential in regulating post-harvest losses in lettuce and spinach. This study provides new insights that can be used for the development of new biostimulants for the sustainable management of post-harvest losses. However, to implement them in post-harvest management, a detailed understanding of the molecular mechanisms of ANE and HA, and their combination, on post-harvest physiology is required.

Supplementary Materials: The following are available online at http://www.mdpi.com/2077-0472/9/11/240/s1, Figure S1. This figure represents the effect of ANE and HA on the yield of lettuce, in terms of fresh weight harvested after 30 days. Different combinations of ANE and HA used for preharvest treatment were as follows: C (control), T1 (0.1\% ANE), T2 (0.25\% ANE), T3 (0.2\% HA), T4 (0.4\% HA), T6 (0.1\% ANE + 0.4\% HA), and T8 $(0.25 \%$ ANE $+0.2 \% \mathrm{HA})$. Each experiment was performed in triplicate, and each experimental unit had six plants. The average of the eighteen values were presented as mean \pm SE and means represented by same letters were not significantly different at $p \leq 0.05$. Figure S2. This figure represents the effect of ANE and HA on yield of spinach, in terms of fresh weight harvested after 35 days. Different combinations of ANE and HA used for preharvest treatment were as follows: C (control), T1 (0.1\% ANE), T2 (0.25\% ANE), T3 (0.2\% HA), T4 (0.4\% HA), T6 (0.1\% ANE $+0.4 \% \mathrm{HA})$, and T8 $(0.25 \%$ ANE $+0.2 \% \mathrm{HA})$. Each experiment was performed in triplicate, and each experimental unit had six plants. The average of the eighteen values were presented as mean \pm SE and means represented by same letters were not significantly different at $p \leq 0.05$. Table S1. Different concentrations of ANE and HA, alone or in combination, were evaluated for their efficacy in improving early growth of lettuce and spinach. 
Author Contributions: Conceived the idea: B.P. Design of experiments: M.S., P.S.S. and B.P. Performed the experiments: M.S. and PS. Performed or assisted with data processing, analysis, and interpretation: M.S., P.S.S., S.Y., S.A. and B.P. Drafted all versions of the manuscript: M.S., P.S.S. and B.P. Contributed to the final versions of the manuscript: M.S., P.S.S., S.A., S.Y. and B.P. All authors critically revised and approved the final version.

Funding: The work reported in this paper was funded by the Nova Scotia Department of Agriculture, Mitacs and Acadian Seaplants Limited, Nova Scotia, Canada.

Acknowledgments: The authors are grateful to Emily Peters (Dalhousie University, Faculty of Agriculture) for her valuable suggestions in preparing the manuscript.

Conflicts of Interest: The authors declare no conflicts of interest. The funders had no role in the design of the study; in the collection, analyses, or interpretation of data; in the writing of the manuscript, or in the decision to publish the results.

\section{References}

1. Van Oosten, M.J.; Pepe, O.; De Pascale, S.; Silletti, S.; Maggio, A. The role of biostimulants and bioeffectors as alleviators of abiotic stress in crop plants. Chem. Biol. Technol. Agric. 2017, 4, 1-12. [CrossRef]

2. Bulgari, R.; Cocetta, G.; Trivellini, A.; Vernieri, P.; Ferrante, A. Biostimulants and crop responses: A review. Biol. Agric. Hortic. 2015, 31, 1-17. [CrossRef]

3. Brown, P.; Saa, S. Biostimulants in agriculture. Front. Plant Sci. 2015, 6, 671. [CrossRef] [PubMed]

4. du Jardin, P. Plant biostimulants: Definition, concept, main categories and regulation. Sci. Hortic. (Amsterdam) 2015, 196, 3-14. [CrossRef]

5. Spinelli, F.; Fiori, G.; Noferini, M.; Sprocatti, M.; Costa, G. A novel type of seaweed extract as a natural alternative to the use of iron chelates in strawberry production. Sci. Hortic. 2010, 125, 263-269. [CrossRef]

6. Khan, W.; Rayirath, U.P.; Subramanian, S.; Jithesh, M.N.; Rayorath, P.; Hodges, D.M.; Critchley, A.T.; Craigie, J.S.; Norrie, J.; Prithiviraj, B. Seaweed extracts as biostimulants of plant growth and development. J. Plant Growth Regul. 2009, 28, 386-399. [CrossRef]

7. Spinelli, F.; Fiori, G.; Noferini, M.; Sprocatti, M.; Costa, G. Perspectives on the use of a seaweed extract to moderate the negative effects of alternate bearing in apple trees. J. Hortic. Sci. Biotechnol. 2009, 84, 131-137. [CrossRef]

8. Hong, D.D.; Hien, H.M.; Son, P.N. Seaweeds from Vietnam used for functional food, medicine and biofertilizer. J. Appl. Phycol. 2007, 19, 817-826. [CrossRef]

9. Shukla, P.S.; Mantin, E.G.; Adil, M.; Bajpai, S.; Critchley, A.T.; Prithiviraj, B. Ascophyllum nodosum-based biostimulants: Sustainable applications in agriculture for the stimulation of plant growth, stress tolerance, and disease management. Front. Plant Sci. 2019, 10, 655. [CrossRef] [PubMed]

10. Rayirath, P.; Allan-Wojtas, P.; Prithiviraj, B.; Mark Hodges, D.; Critchley, A.T.; MacKinnon, S.; Benkel, B. Lipophilic components of the brown seaweed, Ascophyllum nodosum, enhance freezing tolerance in Arabidopsis Thaliana. Planta 2009, 230, 135-147. [CrossRef] [PubMed]

11. Kandasamy, S.; Khan, W.; Evans, F.; Critchley, A.T.; Prithiviraj, B. Tasco ${ }^{\circledR}$ : A product of Ascophyllum nodosum enhances immune response of Caenorhabditis elegans against Pseudomonas aeruginosa infection. Mar. Drugs 2012, 10, 84-105. [CrossRef] [PubMed]

12. Wally, O.S.D.; Critchley, A.T.; Hiltz, D.; Craigie, J.S.; Han, X.; Zaharia, L.I.; Abrams, S.R.; Prithiviraj, B. Regulation of phytohormone biosynthesis and accumulation in Arabidopsis following treatment with commercial extract from the marine macroalga Ascophyllum nodosum. J. Plant Growth Regul. 2013, 32, 324-339. [CrossRef]

13. Tahir, M.M.; Khurshid, M.; Khan, M.Z.; Abbasi, M.K.; Kazmi, M.H. Lignite-Derived humic acid effect on growth of wheat plants in different soils. Pedosphere 2011, 21, 124-131. [CrossRef]

14. Canellas, L.P.; Olivares, F.L.; Aguiar, N.O.; Jones, D.L.; Nebbioso, A.; Mazzei, P.; Piccolo, A. Humic and fulvic acids as biostimulants in horticulture. Sci. Hortic. (Amsterdam) 2015, 196, 15-27. [CrossRef]

15. Khaled, H.; Fawy, H.A. Effect of different levels of Humic Acids on the nutrient content, plant growth, and soil properties under conditions of salinity. Soil Water Res. 2011, 6, 212-219. [CrossRef]

16. Phuong, H.K.; Tichý, V. Activity of humus acids from peat as studied by means of some growth regulator bioassays. Biol. Plant 1976, 18, 1951-1999. [CrossRef]

17. Zhang, X.; Ervin, E.H.; Schmidt, R.E. Seaweed extract, humic acid, and propiconazole improve tall fescue sod heat tolerance and posttransplant quality. Hortic. Sci. 2003, 38, 4404-4443. [CrossRef] 
18. Pishchik, V.N.; Vorobyov, N.I.; Walsh, O.S.; Surin, V.G.; Khomyakov, Y.V. Estimation of synergistic effect of humic fertilizer and Bacillus subtilis on lettuce plants by reflectance measurements. J. Plant Nutr. 2016, 39, 1074-1086. [CrossRef]

19. Billard, V.; Etienne, P.; Jannin, L.; Garnica, M.; Cruz, F.; Garcia-Mina, J.M.; Yvin, J.C.; Ourry, A. Two biostimulants derived from algae or humic acid induce similar responses in the mineral content and gene expression of winter Oilseed Rape (Brassica napus L.). J. Plant Growth Regul. 2014, 33, 305-316. [CrossRef]

20. Zhang, X.; Ervin, E.; Schmidt, R. Physiological effects of liquid applications of a seaweed extract and a humic acid on creeping bentgrass. J. Am. Soc. Hortic. Sci. 2003, 128, 4924-4996.

21. Ferguson, I.; Volz, R.; Woolf, A. Preharvest factors affecting physiological disorders of fruit. Postharvest Biol. Technol. 1999, 15, 2552-2562. [CrossRef]

22. Kader, A.A. Postharvest technology of horticultural crops-An overview from farm to fork. J. Appl. Sci. Technol. 2013, 1, 1-8.

23. Weston, L.A.; Barth, M.M. Preharvest factors affecting postharvest quality of vegetables. HortScience 1997, 32, 812-816. [CrossRef]

24. Fan, D.; Hodges, D.M.; Zhang, J.; Kirby, C.W.; Ji, X.; Locke, S.J.; Critchley, A.T.; Prithiviraj, B. Commercial extract of the brown seaweed Ascophyllum nodosum enhances phenolic antioxidant content of spinach (Spinacia oleracea L.) which protects Caenorhabditis elegans against oxidative and thermal stress. Food Chem. 2011, 124, 195-202. [CrossRef]

25. Fan, D.; Kandasamy, S.; Hodges, D.M.; Critchley, A.T.; Prithiviraj, B. Pre-Harvest treatment of spinach with Ascophyllum nodosum extract improves post-harvest storage and quality. Sci. Hortic. 2014, 170, 70-74. [CrossRef]

26. Fan, D.; Hodges, D.M.; Critchley, A.T.; Prithiviraj, B. A Commercial extract of brown macroalga (Ascophyllum nodosum) affects yield and the nutritional quality of spinach In Vitro. Commun. Soil Sci. Plant Anal. 2013, 44, 1873-1884. [CrossRef]

27. Nikbakht, A.; Kafi, M.; Babalar, M.; Xia, Y.P.; Luo, A.; Etemadi, N.A. Effect of humic acid on plant growth, nutrient uptake, and postharvest life of gerbera. J. Plant Nutr. 2008, 31, 2155-2167. [CrossRef]

28. Shukla, P.S.; Agarwal, P.K.; Jha, B. Improved salinity tolerance of Arachis hypogaea (L.) by the interaction of halotolerant plant-growth-promoting rhizobacteria. J. Plant Growth Regul. 2012, 31, 195-206. [CrossRef]

29. Shukla, P.S.; Gupta, K.; Agarwal, P.; Jha, B.; Agarwal, P.K. Overexpression of a novel SbMYB15 from Salicornia brachiata confers salinity and dehydration tolerance by reduced oxidative damage and improved photosynthesis in transgenic tobacco. Planta 2015, 242, 1291-1308. [CrossRef] [PubMed]

30. Ritchie, R.J. Universal chlorophyll equations for estimating chlorophylls a, b, c, and d and total chlorophylls in natural assemblages of photosynthetic organisms using acetone, methanol, or ethanol solvents. Photosynthetica 2008, 46, 115-126. [CrossRef]

31. Lichtenthaler, H.K.; Buschmann, C. Chlorophylls and Carotenoids: Measurement and Characterization by UV-VIS Spectroscopy. In Handbook of Food Analytical Chemistry; Wiley-Interscience: Hoboken, NJ, USA, 2005; ISBN 9780471709084.

32. Brand-Williams; Cuvelier, M.E.; Berset, C. Use of a free radical method to evaluate antioxidant activity. Food Sci. Technol. 1995, 28, 25-30.

33. Bradford, K.J.; Dahal, P.; Van Asbrouck, J.; Kunusoth, K.; Bello, P.; Thompson, J.; Wu, F. The dry chain: Reducing postharvest losses and improving food safety in humid climates. Trends Food Sci. Technol. 2018, 71, 84-93. [CrossRef]

34. Cardozo, K.H.M.; Guaratini, T.; Barros, M.P.; Falcão, V.R.; Tonon, A.P.; Lopes, N.P.; Campos, S.; Torres, M.A.; Souza, A.O.; Colepicolo, P.; et al. Metabolites from algae with economical impact. Comp. Biochem. Physiol.-Part C: Toxicol. Pharmacol. 2007, 146, 607-608. [CrossRef] [PubMed]

35. Atiyeh, R.M.; Lee, S.; Edwards, C.A.; Arancon, N.Q.; Metzger, J.D. The influence of humic acids derived from earthworm-processed organic wastes on plant growth. Bioresour. Technol. 2002, 84, 71-74. [CrossRef]

36. Hodges, R.J.; Buzby, J.C.; Bennett, B. Postharvest losses and waste in developed and less developed countries: Opportunities to improve resource use. J. Agric. Sci. 2011, 149, 37-45. [CrossRef]

37. Prusky, D. Reduction of the incidence of postharvest quality losses, and future prospects. Food Secur. 2011, 3, 4634-4674. [CrossRef]

38. Hodges, D.M.; Toivonen, P.M.A. Quality of fresh-cut fruits and vegetables as affected by exposure to abiotic stress. Postharvest Biol. Technol. 2008, 48, 1551-1562. [CrossRef] 
39. Mancuso, S.; Azzarello, E.; Mugnai, S.; Briand, X. Marine bioactive substances (IPA extract) improve foliar ion uptake and water stress tolerance in potted Vitis vinifera plants. Adv. Hortic. Sci. 2006, 20, 1000-1006.

40. Bergquist, S.A.M.; Gertsson, U.E.; Olsson, M.E. Influence of growth stage and postharvest storage on ascorbic acid and carotenoid content and visual quality of baby spinach (Spinacia oleracea L.). J. Sci. Food Agric. 2006, 86, 346-355. [CrossRef]

41. Costa, L.; Vicente, A.R.; Civello, P.M.; Chaves, A.R.; Martínez, G.A. UV-C treatment delays postharvest senescence in broccoli florets. Postharvest Biol. Technol. 2006, 39, 204-210. [CrossRef]

42. Khan, W.; Hiltz, D.; Critchley, A.T.; Prithiviraj, B. Bioassay to detect Ascophyllum nodosum extract-induced cytokinin-like activity in Arabidopsis thaliana. J. Appl. Phycol. 2011, 23, 409-414. [CrossRef]

43. Zhang, X.; Ervin, E.H. Cytokinin-Containing seaweed and humic acid extracts associated with creeping bentgrass leaf cytokinins and drought resistance. Crop Sci. 2004, 44, 1737-1745. [CrossRef]

44. Marangoni, A.G.; Palma, T.; Stanley, D.W. Membrane effects in postharvest physiology. Postharvest Biol. Technol. 1996, 7, 193-217. [CrossRef]

45. Shewfelt, R.L.; Del Rosario, B.A. The role of lipid peroxidation in storage disorders of fresh fruits and vegetables. HortScience 2000, 35, 575-579. [CrossRef]

46. Hodges, D.M.; Lester, G.E.; Munro, K.D.; Toivonen, P.M.A. Oxidative stress: Importance for postharvest quality. HortScience 2004, 39, 924-929. [CrossRef]

47. Page, T.; Griffiths, G.; Buchanan-Wollaston, V. Molecular and biochemical characterization of postharvest senescence in broccoli. Plant. Physiol. 2001, 125, 718-727. [CrossRef] [PubMed]

48. Zhang, X.; Schmidt, R.E. Hormone-Containing products' impact on antioxidant status of tall fescue and creeping bentgrass subjected to drought. Crop Sci. 2000, 40, 1344-1349. [CrossRef]

49. Lee, S.K.; Kader, A.A. Preharvest and postharvest factors influencing vitamin C content of horticultural crops. Postharvest Biol. Technol. 2000, 207-220. [CrossRef]

(C) 2019 by the authors. Licensee MDPI, Basel, Switzerland. This article is an open access article distributed under the terms and conditions of the Creative Commons Attribution (CC BY) license (http://creativecommons.org/licenses/by/4.0/). 